\title{
Sarcoma de Kaposi
}

El sarcoma de Kaposi, también llamado Angiosarcoma de Kaposi o sarcoma hemorrágico idiopático múltiple, es una angiomatosis sistemica de evolución maligna, que se manifiesta primariamente como nódulos vasculares múltiples en la piel y otros órganos. Afecta predominantemente a los hombres y tiene distribuciones geográficas enigmáticas.

La enfermedad fue descrita por primera vez por Kaposi (1) como sarcoma pigmentado múltiple e idiopático. Después de la descripción de Kaposi se informaron casos esporádicos. El interés resurgió con el descubrimiento de sarcoma de Kaposi en un cinturón geográfico en Africa (2) y con la epidemia reciente asociada con el Síndrome de inmunodeficiencia adquirida.

Existirían por tanto tres formas polares de Sarcoma de Kaposi con diferencias entre sí: forma clásica, forma endémica (Africana) y epidémica (asociada al SIDA).

\section{FORMA CLÁSICA}

En los comienzos del siglo, se observó que la enfermedad era más común en el sur y el este de Europa que en el norte y el oeste, algunos estudios demostraron que la enfermedad es más frecuente en judíos y en personas de ascendencia mediterránea. Esta hipótesis es discutible. La mayor incidencia se observa en la quinta, sexta y séptima décadas.

Kaposi originalmente describió múltiples placas dérmicas, nódulos y tumores. Estos son rojos o purpúreos en personas de piel clara, y más oscuros que la piel circundante, con un tinte azulado, en personas de piel oscura. A medida que las lesiones envejecen o involucionan adquieren un color parduzco. Las lesiones comienzan como pápulas pequeñas y pueden progresar a placas nódulos o tumores; pueden alcanzar $10 \mathrm{~cm}$. de diámetro o más y varían desde una a ciento, en un paciente determinado.

Los tumores y nódulos pueden estar cubiertos por piel normal, atrófica o pueden ulcerarse, algunos tienen una superficie verrucosa o fungosa. Las lesiones son mas frecuentes en las extremidades inferiores y se extienden centripetamente de forma lenta.
Las lesiones pueden arder, picar o doler, en las localizadas en miembros inferiores el dolor puede limitar la deambulación. El edema es frecuente, especialmente en las piernas y puede ser suficientemente severo para limitar la marcha. Pueden producirse hemorragias espontáneas o secundarias a traumatismos.

Puede estar afectado cualquier órgano interno. La enfermedad puede ser exclusivamente visceral sin lesiones cutáneas. Puede producirse la muerte por enfermedad generalizada con caquexia, hemorragias o alteración de la función de los órganos vitales por el crecimiento tumoral.

\section{FORMA ENDÉMICA (AFRICANA)}

En 1963 Lothe (2) describió un cinturón endémico en Africa tropical, que incluye a Kenia, Tanzania y Zaire, donde la enfermedad es sorprendentemente frecuente, constituyendo hasta el $9 \%$ de todos los tumores malignos, con un pico en la primera década de la vida, no se observan casos en la segunda década, y luego aumenta de forma constante durante toda la vida adulta.

Los casos endémicos de sarcoma de Kaposi se presentan con una diversidad morfológica de lesiones, que pueden ser subclasificadas en cuatro tipos principales: nodulares, floridas, infiltrativas y linfadenopáticas. Esta clasificación morfológica ha servido para identificar clínicamente grupos distintos con cuadros histológicos, historia natural y respuesta al tratamiento diferentes.

El tipo nodular es el más común y puede coexistir con otros tumores más agresivos, es indolente, de respuesta variable al tratamiento y puede ceder espontáneamente. La variedad florida habitualmente es de crecimiento rápido, ulcerada, con infección secundaria, y hemorrágica; estos tumores pueden extenderse profundamente en la dermis y afectar al hueso, responden dramáticamente a la quimioterapia. El tipo infiltrativo habitualmente está limitado a la mano o al pie y se caracteriza por un tumor profundamente invasor, fibrótico, indurado, con un edema carnoso que no deja fóvea; con mucha frecuencia se produce invasión y destrucción del hueso subyacente, estas 
lesiones son duraderas y responden lentamente, si lo hacen, a la quimioterapia. El tipo linfadenopático es más frecuente en niños y adultos jovenes y puede ser confundido clínicamente con un linfoma, pueden producirse o no nódulos cutáneos, los ganglios linfáticos afectados crecen rápidamente y hasta hace poco tiempo esta forma de sarcoma de Kaposi era de mal pronóstico; el uso agresivo de quimioterapia puede producir regresión rápida con algunos sobrevivientes a largo plazo.

\section{FORMA EPIDÉMICA (ASOCIADA AL SIDA)}

La epidemia de SIDA, que a mediados de 1983 comprendió mas de 1.500 casos, originalmente fue anunciada por un elevado número de casos de sarcoma de Kaposi y neumonía por Pneumocystis carinii en varones homosexuales. La asociación de sarcoma de Kaposi y SIDA se basó en la inmunodeficiencia funcional severa, similar a la situación observada en receptores inmunosuprimidos de aloinjertos. Las características clínicas y la evolución de la enfermedad en pacientes con SIDA, difiere de las formas endémica y clásica (3).

El sarcoma de Kaposi en pacientes inmunosuprimidos comienza como una mácula rojiza con palidez perilesional. En una semana la mácula cambia a color púrpura o pardo y desaparece el halo pálido. Los tumores son pequeños, desde apenas unos milímetros a un centímetro, son redondeados, están ligeramente elevados y crecen lentamente en semanas o meses. En raras ocasiones se produce un tumor cutáneo único, frecuentemente en la planta del pie, o en la cabeza y región cervical, pero la mayoría de los pacientes se presentan con múltiples lesiones ampliamente distribuidas por el organismo; ocasionalmente algunos pacientes desarrollan una distribución simétrica en espejo.

Aproximadamente el $10 \%$ de los pacientes presentan afectación ganglionar periférica como una manifestación del sarcoma de Kaposi; en estos casos el tumor es de localización subcapsular o trabecular. Un 50\% de los pacientes desarrolla lesiones en la boca o en el aparato gastrointestinal, son de localización submucosa y de color rojo purpúreo. En pacientes fallecidos con enfermedad cutánea avanzada, el sarcoma de Kaposi se encuentra virtualmente en todos los órganos, excepto el cerebro.

La historia natural de la enfermedad no tratada en pacientes con SIDA es variable. Una minoría que se presenta con una o dos lesiones cutáneas se mantiene estable durante algunos años. Habitualmente las lesiones crecen lentamente y aparecen nuevos tumores en un lapso de semanas a meses

\section{ETIOPATOGENIA}

Desde hace mas de veinte años se ha pensado que algún virus estaba implicado en la patogenia del sarcoma de Kaposi, y que este virus podría ser transmitido por vía sexual (4). Son numerosos los agentes infecciosos a los que se ha intentado atribuir un papel en el desencadenamiento de las lesiones de sarcoma de Kaposi: citomegalovirus (5), virus del papiloma humano tipo 16 (6), virus herpes humano tipo 6 (7), Mycoplasma penetrans (8) y virus BK (9). En 1994 Chang y cols. descubrieron la presencia de ADN de un nuevo tipo de virus herpes (VHH-8) en muestras cutáneas de sarcoma de Kaposi, a partir de ese momento se ha descrito la presencia de dicho virus en todas las formas de Kaposi (11-22), tanto clásicas como endémicas, virus que parece ser condición necesaria, pero no suficiente para el desarrollo de la enfermedad, necesitando una seroconversión, que parece inducida por el déficit inmunitario que provoca la infección por el HIV (22-24) mecanismo que también se produce en las formas iatrogénicas de sarcoma de Kaposi debido a los tratamientos inmunosupresores en enfermos trasplantados, remitiendo las lesiones al suspender los tratamientos inmunosupresosres y en los enfermos de SIDA al mejorar su inmunidad con las tratamiento antiretrovirales $(28,29)$. Este virus produciría una interleuqina similar a la interleuqina 6 humana, que induce crecimiento endotelial vascular $(30,31)$.

Por otro lado existen estudios $(24,26)$ que vinculan el desarrollo de lesiones de angiosarcoma de Kaposi no solo al déficit inmunitario, sino que plantean una colaboración del HHV-8 con el virus de la inmunodeficiencia humana, siendo este un colaborador necesario, a través de su proteína Tat para el desarrollo de las lesiones de Kaposi. Un tema distinto seria el método de transmisión del HHV-8, que la mayoría de autores (32-34) plantean por vía de transmisión sexual, fundamentalmente practicas homosexuales entre varones, no encontrándose partículas virales en poblaciones heterosexuales, aunque en algunos estudios se ha demostrado transmisión vertical madre-hijo.

\section{TRATAMIENTO}

Aparte de los clásicos tratamientos mediante cirugía, radioterapia o quimioterapia, la importante incidencia de angiosarcoma de Kaposi en enfermos de SIDA, cuya situación no es en muchos de los casos la más adecuada para soportar tratamientos agresivos, con efectos secundarios importantes, ha provocado la búsqueda de diferentes tratamientos para este proceso

La propia terapia antiretroviral (HAART) $(28,29)$, al mejorar la situación inmune de los enfermos de SIDA con la disminución de carga viral en estos pacientes, parece mejorar, incluso con remisiones parciales las lesiones de sarcoma de Kaposi que presentan estos enfermos. también se ha usado el interferón alfa, tanto por vía sistémica (35) como en inyecciones locales (36), quimioterapia con doxorubicin y daunorubicin $(25,37,38)$. La talidomida ha sido usada en el intento de bloquear la actividad de sustancias angiogenicas como bFGF, VEGF e IL-6. Derivados del ácido retinoico por vía oral (35) y tópica en forma de gel de alitretinoina (39), terapia fotodinámica con Photofrin (40), aplicación tópica de 1 alfa, 25, dihidroxivitamina D (41), laserterapia, crioterapia, quelantes del hierro $(42,43)$ y la posibilidad de que la gonadotropina corionica humana pueda usarse por sus efectos en la microcirculación, describiéndose en la orina de las mujeres embarazadas proteínas con actividad antineoplasica, que podrían explicar la baja incidencia de este proceso entre el sexo femenino $(44,45)$.

\section{MORA MORILLAS}

Instituto de Enfermedades y Cirugía de la Piel. Hospital Clínico de San Carlos. Universidad Complutense. Madrid 


\section{Bibliografía}

1. Kaposi M. Idiopathisches multiples pigmentsarkom der Haut Arch Derm Syph 1872; 4: 265.

2. Lothe F. Kaposi's sarcoma in Uganda africans. Acta Pathol Microbiol Scand 1963; (Supl.) 161: 5

3. Friedman-Kien AE. Disseminated Kaposi's sarcoma in homosexual men. Ann Intern Med 1982; 96: 693.

4. Beral V: Kaposi's sarcoma among persosn with AIDS: a sexualy transmited infection? Lancet 1990; 335: 123-8.

5. Grody WW. Detection of cytomegalovirus DNA in classisc and epidemic Kaposi's sarcoma by in situ hybridation. Hum Pathol 1988; 19: 524-8.

6. Huang YQ. HPV-16 related DNA sequences in Kaposi's sarcoma. Lancet 1992; 339: 515-8

7. Kempf W. Human herpes virus type 6 and cytomegalovirus in AIDSassociated Kaposi's sarcoma: no evidence for an etiological association. Hum Pathol 1995; 26: 914-9.

8. Yuang-Hu WR. Mycoplasma penetrans infection in male homosexuals with AIDS. hig seroprevalence and association with Kaposi's sarcoma. Clin Infect Dis 1993; 17: 724-9.

9. Monini P. Latent BK virus infection and Kaposi's sarcoma. Br J Cancer 1996; 66: 717-22.

10. Chang Y. Identification of herpesvirus-like DNA sequences in AIDSassociated Kaposi's sarcoma. Science 1994; 266: 1865-9.

11. Diociaiuti A. HHV8 in renal transplant recipients. Transpl Int 2000; 13 (supl. 1) :410-2.

12. Engels EA. Latent class analysis of human herpesvirus 8 assay perfomance and infection prevalence in sub-saharan Africa and Malta. Int J cancer 2000; 88 (6): 1003-8.

13. Pugliese A. Human herpesvirus 8 and associated diseases in a group of 67 human inmunodeficiency virus-seropositive individuals. Cancer detect Prev 2000; 24 (3): 258-65.

14. Galetskii SA. PCR diagnosis of sequences of a novel human herpes virus type 8 in patients with Kaposi sarcoma in Russia. Vopr Virusol 2000; 45 (4): 13-7.

15. Gruffat H. Kaposi's sarcoma-associated herpesvirus and Kaposi's sarcoma. Microbes Infect 2000; 2 (6): 671-80

16. Cathomas G. Human herpes virus8: a new virus discloses its face. Virchows Arch 2000; 436 (3): 195-206.

17. Insabato L. Primary Kaposi sarcoma of the bowel in a HIV-negative patient. J Sur Oncol 2001; 76 (3): 197-200.

18. Meng YX. Molecular characterization of strains of human herpesvirus 8 fron Japan, Argentina y Kuwait. J Gen Virol 2001; 82: 499-506.

19. Bezold G. Quantitation of human herpes virus 8 DNA in paraffinembedded biopsies of HIV-associated and classical Kaposi's sarcoma by PCR. J Cutan Pathol 2001; 28 (3): 127-30.

20. Davidovici B. Seroepidemiology and molecular epidemiology of Kaposi's sarcoma-associated among Jewish population groups in Israel. J Natl Cancer Inst 2001; 93 (3): 194-202.

21. Cattani P. Kaposi's sarcoma associated with previous human herpesvirus 8 infection in kidney transplat recipients. J Cli Microbiol 2001; 39 (2): 506-8.

22. Diociaiuti A. HHV8 in renal transplant recipients. Transpl. Int. 2000

23. Campbell TB. Relationship of human herpesvirus 8 peripheral blood virus load and Kaposi's sarcoma clinical stage. AIDS 2000; 14 (14): 2109-16.

24. Morini M. Kaposi's sarcoma cells of different etiologics origins respond to HIV-Tat Through the Flk-1/KDR (VEGFR-2): relevance in AIDS-KS phatology. Biochem Biophys Res Commun 2000; 273 (1): 267-71.
25. Dezube BJ. The role of human inmunodeficiency virus-I in the pathogeneis of acquired inmunodeficiency syndrome -related Kaposi's sarcoma: the importance of an inflamatory and angiogenic milieu. Semin Oncol 2000; 27 (4): 420-3.

26. Huag LM. Reciprocal regulatory interaction between human herpesvirus 8 and human inmunodeficiency virus type 1 . J Biol Chem 2001; 276 (16): 13427-32.

27. Gascon P. Kaposi's sarcoma. New treatment modalities. Dermatol Clin 2000; 18 (1): 169-75.

28. International Collaboration on HIV an Cancer. Highly active antiretroviral therapy and incidence of cancer in human immunodeficiency virus-infected adults. J Natl Cancer Inst 2000; 92 (22): 1823-30.

29. Goedert JJ. The epidemiology of acquired immunodeficiency syndrome malignancies. Semin Oncol 2000; 27 (4): 390-401.

30. Aoky Y. Viral and celular cytokines in AIDS related malignant lymphmatous effusions. Blood 2000; 96 (4): 1599-601.

31. Aoky Y. Kaposi's sarcoma -associated herpesvirus-encoded interleukin-6. J. Hematother. Stem Cell Res 2000; 9 (2): 137-45.

32. Martin JN. Invited comentary: determining specific sexual practices associated with human herpesvirus 8 transmssion. Am J Epidemiol 2000; 151 (3): 213-24.

33. Brambilla L. Human herpesvirus- 8 infection among heterosexual partners of patients with classical Kaposi's sarcoma. Br J Dermatol 2000; 143 (5): 1021-5.

34. Plancoulaine S. Human herpesvirus 8 transmision from mother to child and between siblings in an endemic population. Lancet 2001; 353 (9252): 307

35. Somos S. Immunomodulatory treatment with low-dose interferon-alfa and oral retinoic acid in lymphangioma-like Kaposi's sarcoma. Anticancer Res. 2000; 20 (1B): 541-5.

36. Cajade Frias J. Sarcoma de Kaposi clásico en el arrea ORL. Acta Otorrinolaringol Es 2000; 51 (7): 662-4.

37. Cheung TW. AIDS-related Kaposi's sarcoma: a phase II study of liposomal doxorubicin. The TLC D-99 Study Group. Cli Cancer Res 1999; 5 (11): 3432-7.

38. Avilés JA, Recarte C, Pastor L, Lázaro P, De Portugal J. Características del sarcoma de Kaposi. Estudio retrospectivo en un hospital de Tercer Nivel. An Med Interna (Madrid) 2003; 20: 170-4.

39. Walmsley S. Treatmente of AIDS-related cutaneous Kaposi's sarcoma with topical alitretinoin (9-cis retinoic acid) gel. Panretin Gel North American study Group. J Acquir Immune Defic Syndr 1999; 22 (3): 235-46.

40. Bernstein ZP. Photofrin photodinamic therapy for treatment of AIDS-related cutaneous Kaposi's sarcoma. AIDS 1999; 13 (13): 1697-704.

41. Msood R. Kaposi sarcoma is a therapeutic target for vitamin $\mathrm{D}(3)$ receptor agonist. Blood 2000; 96 (9): 3188-94.

42. Ziegler JL. Kaposi's sarcoma, oncogenic viruses, and iron. J Clin Virol 2001; 20 (3): 127-30.

43. Simonart T. Iron chelators inhibit the growth and induce the apoptosis of Kaposi's sarcoma cells and of their putative endothelial precursors. J Invest Dermatol 2000; 115 (5): 893-900.

44. Silvestris N. AIDS-related Kaposi's sarcoma: principal pathogenic mechanisms. J. Exp. Clin. Cancer Res 1999; 18 (3): 311-5.

45. Pati S. Urinary proteins with pro-apoptotic and antitumor activity. Apoptosis 2000; 5 (1): 21-8. 